\title{
Effect of Punch Shape on Multiprocess Tube Flaring for Eccentric Parts*1
}

\author{
Shohei Tamura*2,*3, Keinosuke Iguchi*4 and Masaaki Mizumura*5 \\ Steel Research Laboratories, Nippon Steel \& Sumitomo Metal Corporation, Futtsu 293-8511, Japan
}

\begin{abstract}
In this work, by focusing on multiprocess tube flaring for eccentric parts, we studied the effect of punch shape on deformation behavior by finite element analysis. In the case of using only the eccentric punch, thickness deviation occurs in the circumferential direction and thickness reduction is suppressed because the tube is greatly expanded at the $180^{\circ}$ circumferential position. However, it is found that the thickness deviation and thickness reduction are suppressed by evenly expanding both sides using a concentric punch. Furthermore, although the punch shoulder radius has a negligible effect on formability, it is confirmed that the deformation near the tube edge transitions from uniaxial tension to pure shear as the punch semiangle is increased. The above result clarify that by using concentric punches with punch semiangle larger than the taper angle of the part shape from the initial process, the thickness reduction is drastically minimized compared with other forming methods. [doi:10.2320/matertrans.P-M2020848]
\end{abstract}

(Received May 7, 2020; Accepted July 16, 2020; Published September 29, 2020)

Keywords: tube forming, forming property, flaring, deformation behavior, process design, punch shape, multiprocess, eccentric parts

\section{Introduction}

In recent years, to improve fuel efficiency reducing weight of automotive body and collision safety, the application enlargement of high strength steel tubes are required. In addition, the realization of parts integration with large deformation processing is also required. To achieve these, improvement of formability in tube forming is significant. Thus, in this paper, we focused on tube flaring, which is one of tube forming methods.

For tube flaring, there are various forming methods such as press, spinning and so on. ${ }^{1)}$ In particular, tube flaring using a press has been widely studied for many years because it is a simple and highly productive method. For example, Nishimura et $a l^{2)}$ examined the forming limit due to fracture by performing tube flaring on the open end after cylindrical cup drawing of pure aluminum sheet. Manabe et al. ${ }^{3-7)}$ examined the effect of material properties ( $n$-value and $r$ value), punch semiangle, lubricant and tube end surface on forming load and deformation behavior of stress-strain distribution in tube flaring with a conical punch. In any of the studies, although uniform deformation of concentric shape in the circumferential direction is examined, nonuniform deformation of eccentric shape in the circumferential direction is not. Moreover, in the case of part shape with large expansion and eccentricity, forming in one process is difficult because forming defects such as fracture, wrinkles and buckling occur. To prevent forming defects, forming in multiprocess is considered to be effective. However few studies have discussed the guidelines of design and formability in multiprocess tube flaring.

\footnotetext{
${ }^{* 1}$ This Paper was Originally Published in Japanese in J. JSTP 60 (2019) 182-186.

${ }^{* 2}$ Corresponding author, E-mail: tamura.g3y.shohei@jp.nipponsteel.com

*3Present address: Steel Research Laboratories, Nippon Steel Corporation, Futtsu 293-8511, Japan

${ }^{* 4}$ Present address: Nippon Steel Europe GmbH, Düsseldolf 40547, Germany

${ }^{* 5}$ Present address: Department of Mechanical Engineering, National Institute of Technology (KOSEN), Kure College, Kure 737-8506, Japan
}

So, in this work, we focus on multiprocess tube flaring of the expanded eccentric parts, and the effect of punch shape such as punch semiangle and punch shoulder radius on deformation behavior such as strain distribution near the tube edge is investigated using finite element (FE) analysis.

\section{FE Analysis Method}

Figure 1 shows the shape of the part for multiprocess tube flaring processing. The maximum expansion rate $\lambda_{\max }$ of the part is about $80 \%$. The expansion rate $\lambda$ is defined by the equation:

$$
\lambda=\left(\frac{d-d_{0}}{d_{0}}\right) \times 100(\%)
$$

where $d_{0}$ denotes initial outer diameter of the original tube, and $d$ is outer diameter after expansion. In addition, the eccentricity of the part is $8.9 \mathrm{~mm}$ and it has a shape that is not expanded on the $0^{\circ}$ side in the circumferential direction.

Test materials used in this study are electric resistance welded tubes (22.2 $\mathrm{mm}$ in outer diameter, $1.19 \mathrm{~mm}$ thick) of ferritic stainless steel SUS409L. Table 1 shows the mechanical properties in longitudinal direction obtained by uniaxial tension test using JIS 14C-type tubular specimens (insert a mandrel into the grip). In addition, the parameters obtained by approximating the stress-strain curve using the Swift's hardening law are also shown.

By the way, it is known that the material texture for ferritic stainless steel does not change even after welding and weld

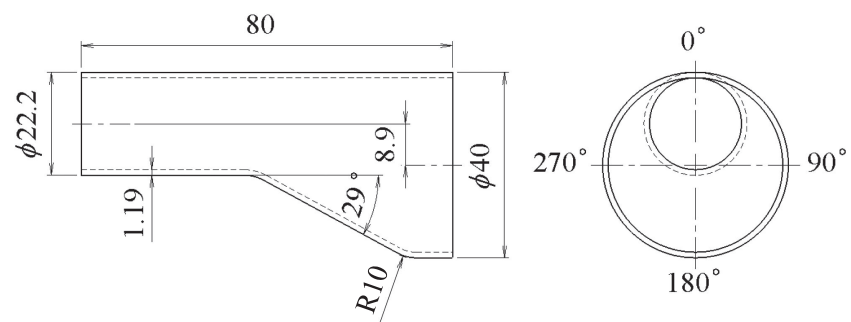

Fig. 1 Shape of eccentric flaring parts. 
Table 1 Mechanical properties of SUS409L tube.

\begin{tabular}{c|l|r}
\hline \multicolumn{2}{l|}{ Tensile strength $/ \mathrm{MPa}$} & 459 \\
\hline \multicolumn{2}{l|}{ Total elongation $/ \%$} & 36.7 \\
\hline \multirow{2}{*}{$\begin{array}{c}\text { Swiff's law } \\
\bar{\sigma}=k\left(\varepsilon_{0}+\bar{\varepsilon}\right)^{n^{*}}\end{array}$} & $k$ value $/ \mathrm{MPa}$ & 681 \\
\cline { 2 - 3 } & $\varepsilon_{0}$ value & 0.179 \\
\cline { 2 - 3 } & $n^{*}$ value & 0.233 \\
\hline
\end{tabular}

zone does not harden. ${ }^{8)}$ This is because ferritic stainless steel generally has a stable ferrite phase in a wide range of compositions and temperatures. So, the deformation resistance of weld zone and heat affected zone is not particularly considered and it was same as the characteristic of base material.

The dynamic explicit method of LS-DYNA Ver. 971 is used for FE analysis. The element type was complete integral shell, and the integration point in the thickness direction was 5 points. The element size was $1 \mathrm{~mm}$ intervals in the longitudinal direction, and the circumferential direction was divided into 70 parts (about $1 \mathrm{~mm}$ intervals) (total number of elements is 8400). To simplify the discussion, the material model assumed an isotropic material, and we used the von Mises's yield function and the Swift's hardening law (see in Table 1). The friction coefficient $\mu$ between tube and tools (punches and dies) was 0.1 , and the moving velocity of punches and upper die was $1000 \mathrm{~mm} / \mathrm{sec}$. Furthermore, the clearance between tube and dies was zero. Moreover, to prevent movement and distortion, the displacement and rotation in the three-axial directions were constrained at all nodes on the edge face in the side that were not expanded.

\section{FE Analysis Results and Discussions}

\subsection{Forming only with an eccentric punch}

In this study, to reduce the die cost, we used the dies of only one type that had the same shape as part shape, and punch shape was exchanged in each step.

First of all, we examined forming only with an eccentric punch (CASE A). Nakamura et al. ${ }^{9)}$ reported that the maximum expansion rate $\lambda_{\max }$ in one step of tube flaring is preferably $25 \%$ or less. Based on the above, the expansion rate $\lambda$ in each step is $25 \%, 50 \%, 75 \%$ and $80 \%$, respectively, and forming is carried out in four steps total. Moreover, the longitudinal distance of the taper of the part shape is set to be same as the longitudinal distance of the punch taper in all steps, therefore the punch semiangle $\alpha$ in each step is $10^{\circ}$, $19^{\circ}, 27^{\circ}$ and $29^{\circ}$, respectively. The punch shoulder radius is $10 \mathrm{~mm}$. Figure 2 shows the schematic illustration of die construction in CASE A. Figure 3 shows the punch shapes in each step in CASE A.

Figure 4 shows the distribution of thickness reduction along the circumferential direction at the tube edge after each step in CASE A, and Fig. 5 shows contours of thickness reduction after the final step in CASE A. In addition, the position of the part end is indicated by a broken line in the figure. The thickness reduction $t_{r}$ is defined by the equation:

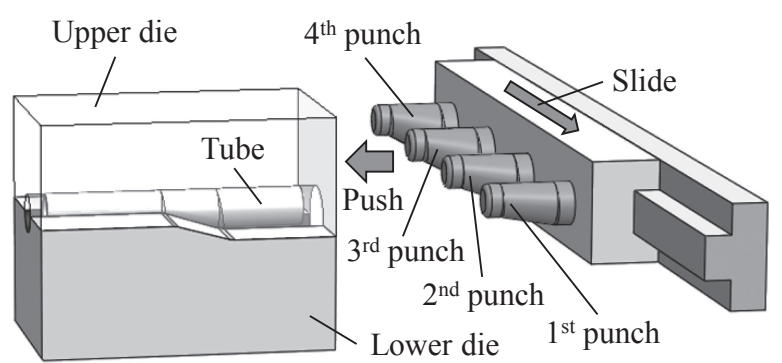

Fig. 2 Die construction in CASE A.

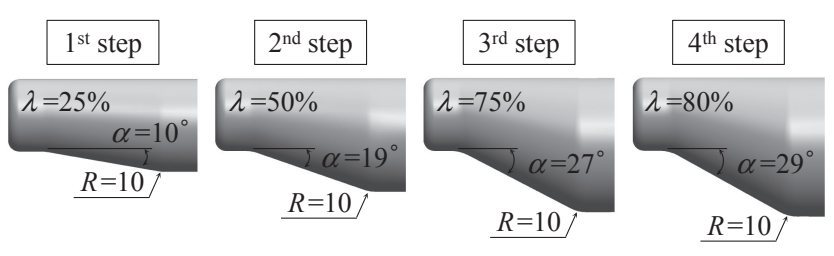

Fig. 3 Punch shapes in CASE A.

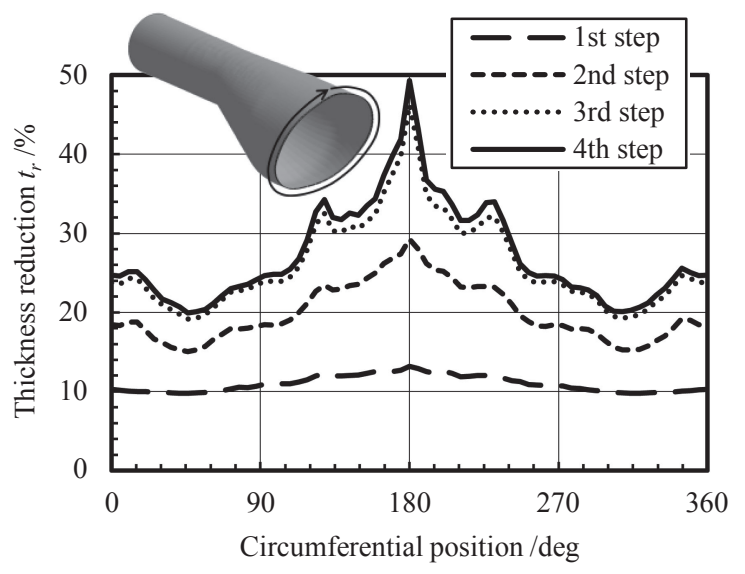

Fig. 4 Distribution of thickness reduction along the circumferential direction at the tube edge after each step in CASE A.

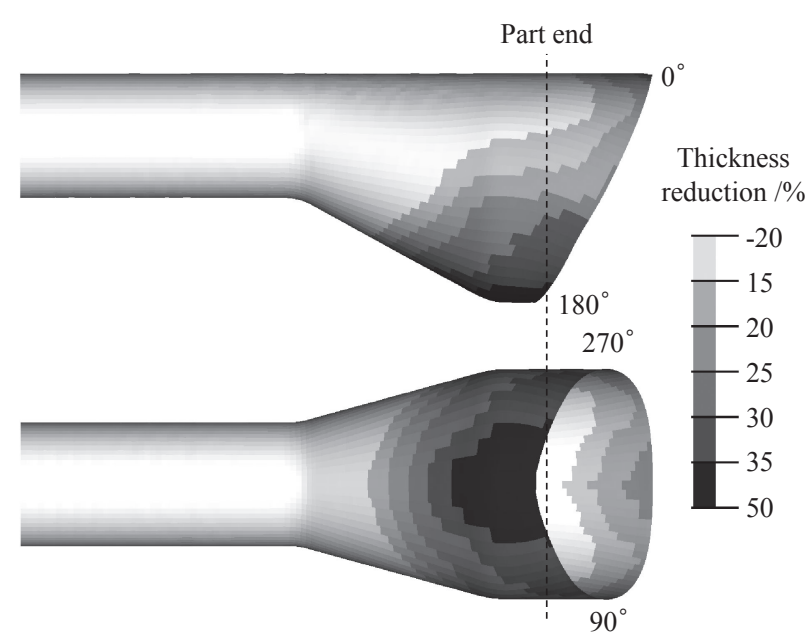

Fig. 5 Contours of thickness reduction after final step in CASE A.

$$
t_{r}=\left(\frac{t_{0}-t}{t_{0}}\right) \times 100(\%)
$$

where $t_{0}$ denotes initial thickness of the original tube, and $t$ is the thickness after expansion. This part is not expanded at the 


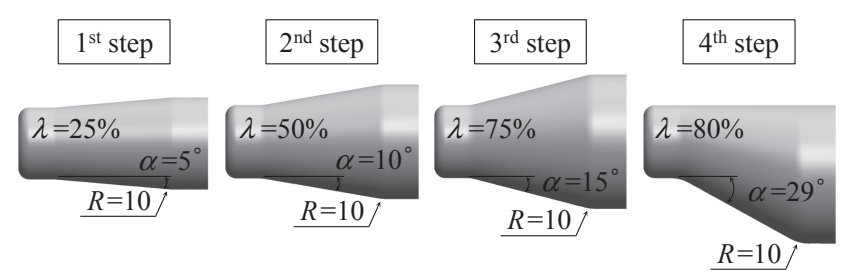

Fig. 6 Punch shapes in CASE B.

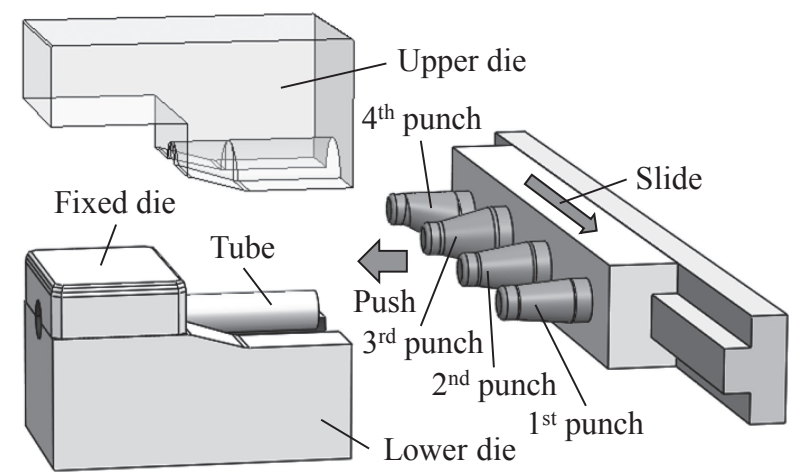

Fig. 7 Die construction in CASE B.

$0^{\circ}$ circumferential position but expanded at the $180^{\circ}$ circumferential position, so thickness reduction is larger. Moreover, the end face is formed obliquely because the amount of material flow into the longitudinal direction differs depending on the circumferential position.

\subsection{Forming with concentric punch}

As shown in the above section, to suppress uneven deformation in the circumferential direction (thickness deviation) seen in forming only with an eccentric punch, we examined a forming method which does not expand the tube to one side in the circumferential direction but expands it uniformly to both sides using a concentric punch and then expands it using an eccentric punch (CASE B). Figure 6 shows the punch shapes in CASE B. As in CASE A, the expansion rate $\lambda$ in each step is $25 \%, 50 \%, 75 \%$ and $80 \%$, respectively, and forming is carried out in four steps totals. Moreover, the longitudinal lengths of the punch taper in all steps are set to be the same as that of the final shape, therefore the punch semiangle $\alpha$ in each step is $5^{\circ}, 10^{\circ}, 15^{\circ}$ and $29^{\circ}$, respectively. In addition, forming with concentric punch (first step to third step) is performed with only the straight portion of the upper die was fixed as shown in Fig. 7 and the upper die opened. This is because the die structure in CASE A cannot expand the tube concentrically. After that the upper die is clamped just before the final step, and an eccentric punch for the final shape is inserted.

Figure 8 shows the distribution of thickness reduction along the circumferential direction at the tube edge after each step. In CASE B, it can be seen that the tube is uniformly expanded around the entire circumference and the thickness is uniformly reduced as the part is formed by concentric punches from the first step to the third step. Furthermore, Fig. 9 shows the deformation behavior before and after die clamping in the fourth step. Although the tube edge face is shaped perpendicular to the longitudinal direction at the end

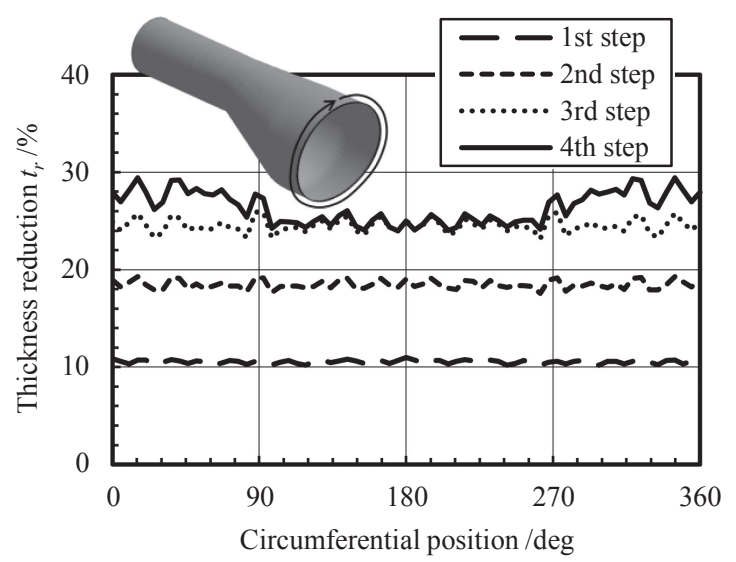

Fig. 8 Distribution of thickness reduction along the circumferential direction at the tube edge after each step in CASE B.

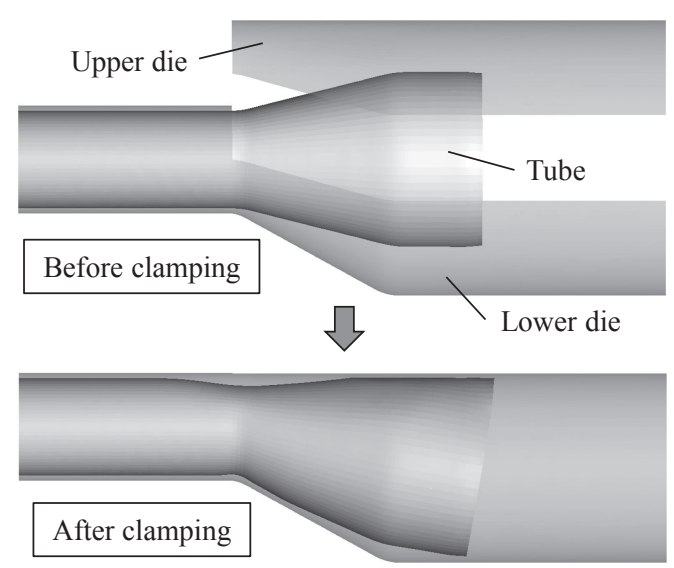

Fig. 9 Deformation behavior before and after upper die clamping in CASE B.

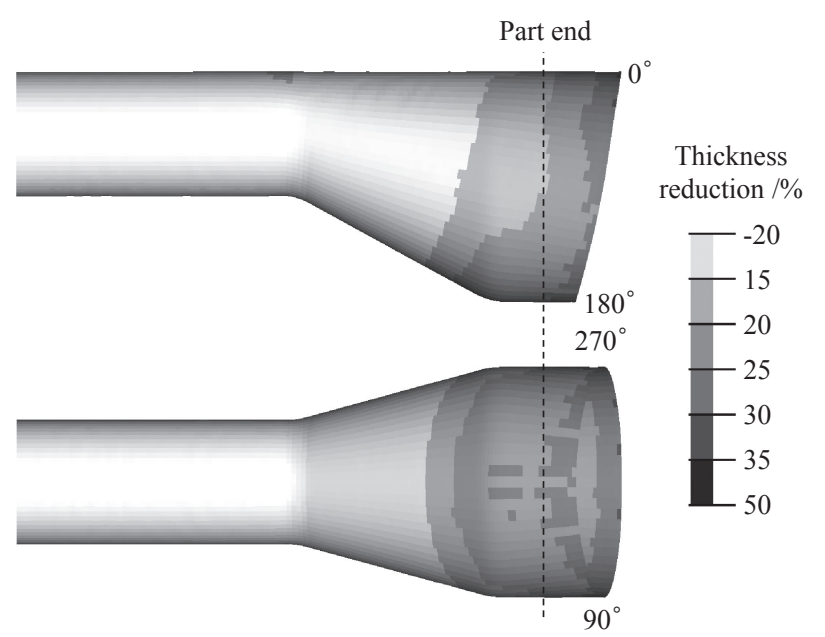

Fig. 10 Contours of thickness reduction after final step in CASE B.

of the third step (before die clamping), bending deformation occurs in the tube during upper die clamping. As a result, the tube edge face is shaped obliquely. After that, although the thickness are reduced in the circumferential direction ununiformly by using an eccentric punch, thickness reduction is drastically suppressed near the $180^{\circ}$ position in the circumferential direction compared with CASE A using only eccentric punches. Figure 10 shows contours of thickness 
reduction after the fourth step. Thickness reduction at part end in CASE B is suppressed than that of CASE A, and it was confirmed that the inclination angle of the tube edge face is smaller. This is because the bias of material flow in the circumferential direction is suppressed by using concentric punches.

\subsection{Effect of punch semiangle and punch shoulder radius}

As mentioned in the above section, it was found that thickness deviation is drastically suppressed by simultaneously using concentric punches compared with forming only with eccentric punches. In addition, the effect of punch shape (punch semiangle $\alpha$ and punch shoulder radius $R$ ) on formability was investigated for the purpose of further improving thickness reduction. In particular, FE analysis with various $\alpha$ and $R$ values was carried out by using concentric punches with $25 \%$ expansion rate. Moreover, if $\alpha$ exceeds $50^{\circ}$, curling deformation ${ }^{10)}$ may occur at tube edge, so it was set to $50^{\circ}$ at the maximum. In addition, when confirming the effect of $\alpha, R$ was fixed at $5 \mathrm{~mm}$, and when confirming the effect of $R, \alpha$ was fixed at $30^{\circ}$, and only each parameter was changed.

Figure 11 shows the strain distribution in the range of $5 \mathrm{~mm}$ from the tube edge on the parts expanded in one step using various shaped punches. In this figure, the plot points close to uniaxial tension deformation indicate the tube edge side. In tube flaring process, the punch is pushed-in longitudinally and the tube is expanded circumferentially, so strain field becomes to be of longitudinal compression and circumferential tension. In terms of the effect of $\alpha$, when

(a)

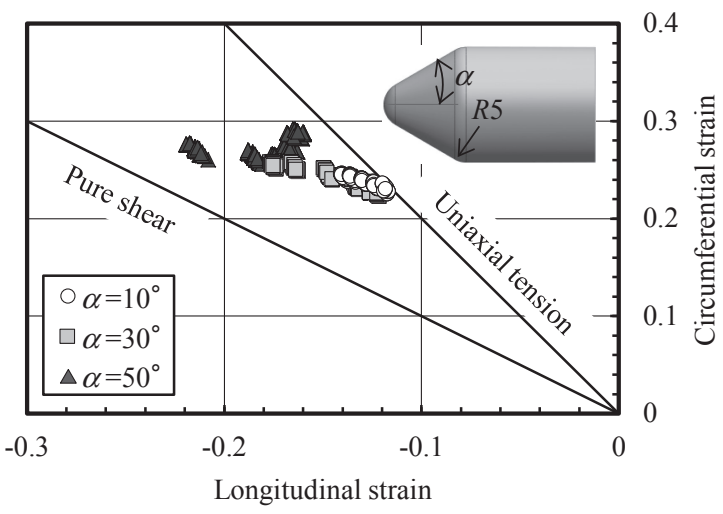

(b)

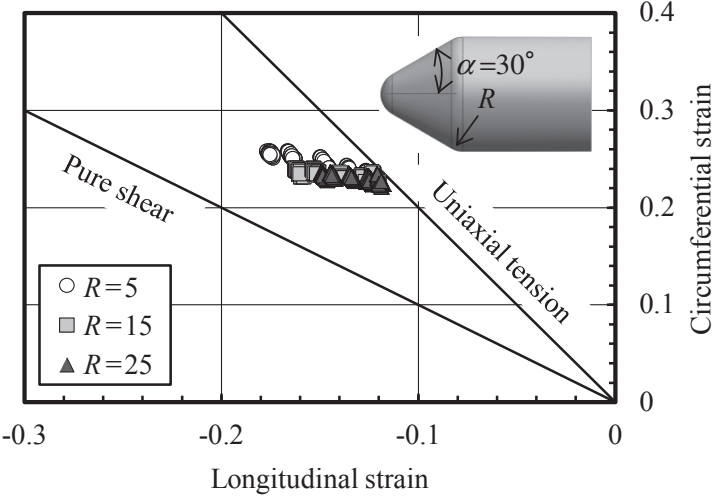

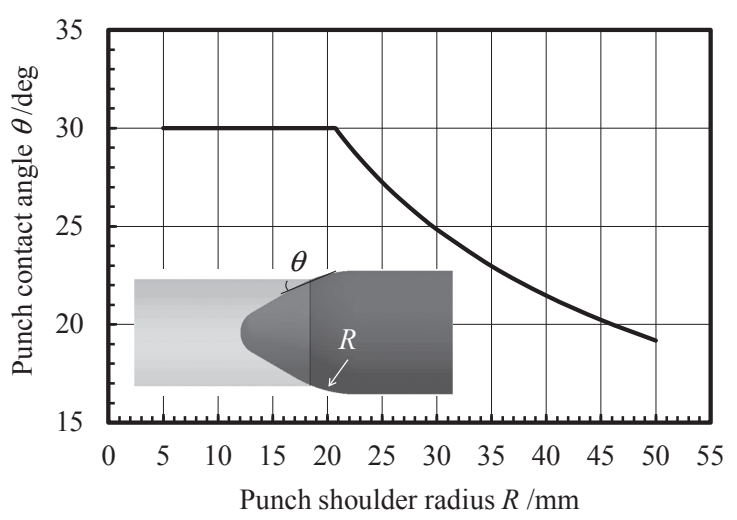

Fig. 12 Punch contact angle in the case of changing punch shoulder radius.

$\alpha$ is as small as $10^{\circ}$, the deformation is close to uniaxial tension, but the longitudinal compressive strain occurred near the tube edge increases as $\alpha$ increases. As a result, it was confirmed that the deformation transitions from uniaxial tension to pure shear. In other words, this means that the change of thickness is small.

On the other hand, the effect of the change in $R$ on the strain distribution is smaller than that in $\alpha$, and it can be seen that, the compressive strain in the longitudinal direction decreases slightly as $R$ increases. Figure 12 shows the punch contact angle $\theta$ in the case of changing $R$. When $R$ is less than $20.7 \mathrm{~mm}$, the tube edge comes into contact with a punch taper at $\theta=30^{\circ}$ being same as the setting value of $\alpha$. In contrast, when $R$ is larger than $20.7 \mathrm{~mm}$, the contact position of the tube edge makes a transition from the punch taper to the punch shoulder as $R$ increases, and it is found that $\theta$ becomes smaller than $\alpha$. As a result, it is considered that the compressive force occurring in the longitudinal direction reduces, and the longitudinal compressive strain decreases slightly.

From the above result, further suppressive effect of thickness reduction is expected by making the punch semiangle $\alpha$ as large as possible without causing curling deformation in tube flaring process.

\subsection{Forming with developed method}

Since the taper angle of the part shape studied this time is $29^{\circ}$, the punch with punch semiangle $\alpha$ of $29^{\circ}$ or less is used in general. However, based on the study results in the above section, we examined a developed method, in which a concentric punch with punch semiangle $\left(\alpha=50^{\circ}\right)$ larger than the taper angle $29^{\circ}$ of the part shape is used from the initial step (CASE C). Figure 13 shows the punch shapes in each step in CASE C. The number of forming steps and the

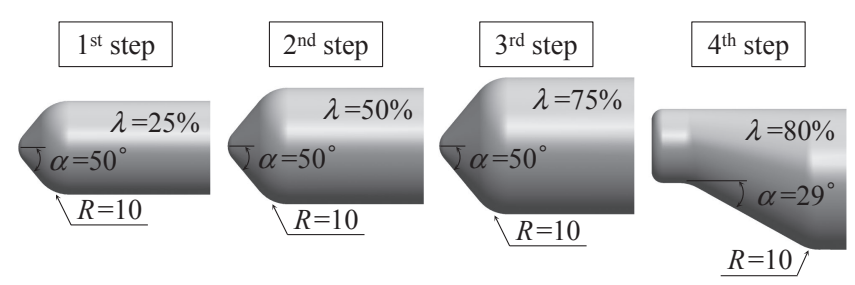

Fig. 13 Punch shapes in CASE C.

g. 11 Strain distribution of forming sample near tube edge. (a) Effect of punch semiangle. (b) Effect of punch shoulder radius. 


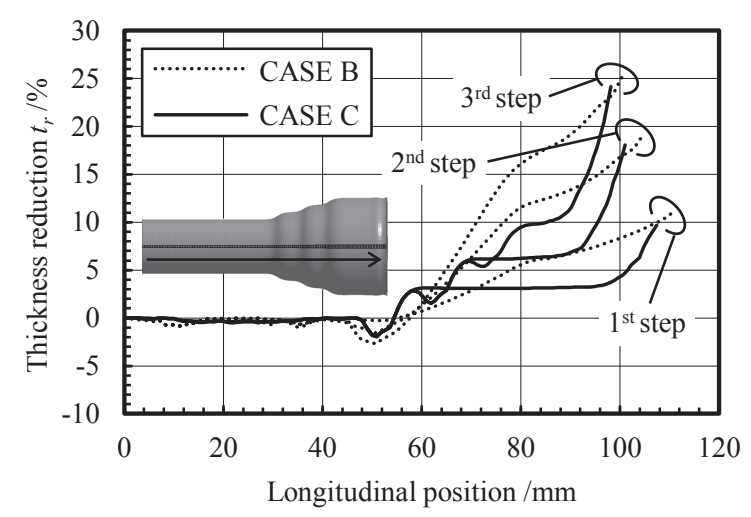

Fig. 14 Distribution of thickness reduction along the longitudinal direction at the $180^{\circ}$ circumferential position for the concentric flaring process in CASE B and CASE C.

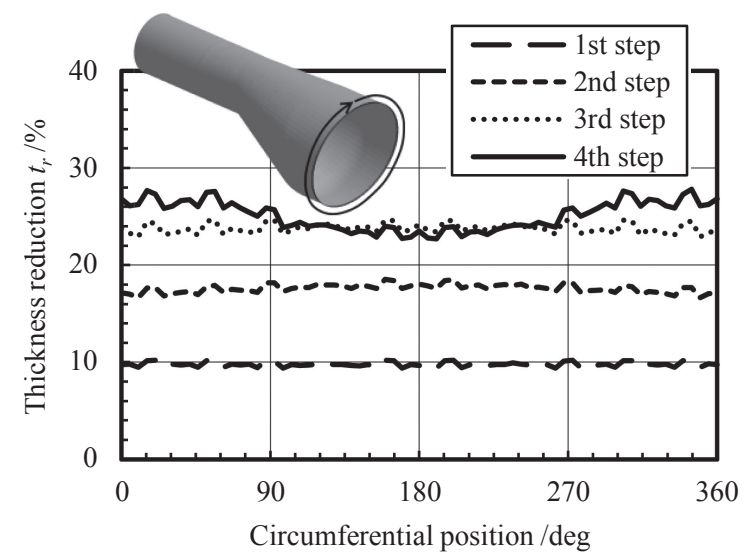

Fig. 15 Distribution of thickness reduction along the circumferential direction at the tube edge after each step in CASE C.

maximum expansion rate in each step were the same as in the other cases.

First of all, to confirm suppressive effect of thickness reduction due to the difference in the punch semiangle, the deformation behavior in the tube flaring process using a concentric punch was compared. Figure 14 shows the distribution of thickness reduction along the longitudinal direction at the $180^{\circ}$ circumferential position for the concentric flaring process in CASE B and CASE C. In terms of thickness reduction rate at the tube edge, although there is little difference due to the difference in $\alpha$, it was confirmed that thickness reduction is suppressed by using a concentric punch with large punch semiangle in the range of about $30 \mathrm{~mm}$ from the tube edge. Furthermore, it can be seen that the effect increases as the tube flaring process progresses.

Next, Fig. 15 shows the distribution of thickness reduction along the circumferential direction at the tube edge after each step in CASE C. Figure 16 shows the contours of thickness reduction after final step in CASE C. Although thickness reduction at the tube edge is not much different from CASE B, thickness reduction is further suppressed near the part end. Furthermore, Fig. 17 shows the distribution of thickness reduction of part end in final step along circumferential direction for each case. The thickness reduction in CASE $\mathrm{C}$ is significantly suppressed compared to CASE A

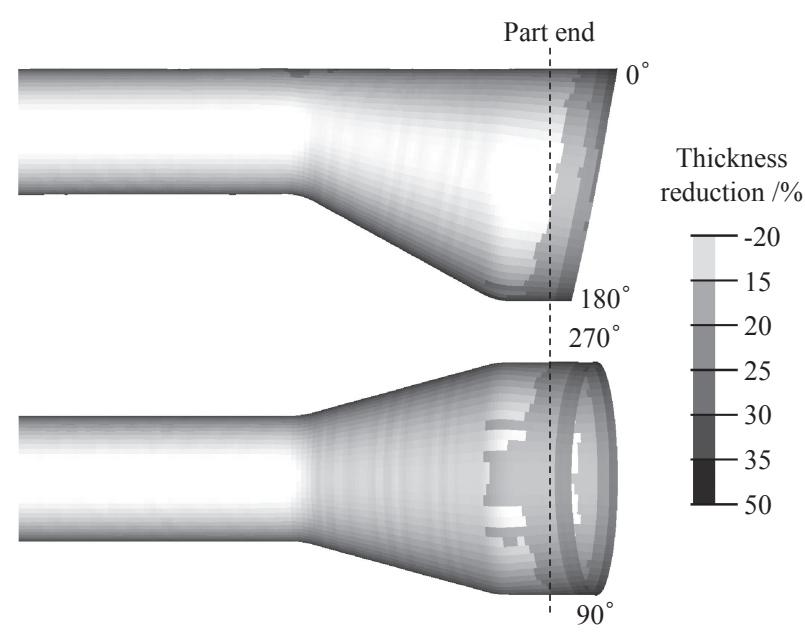

Fig. 16 Contours of thickness reduction after final step in CASE C.

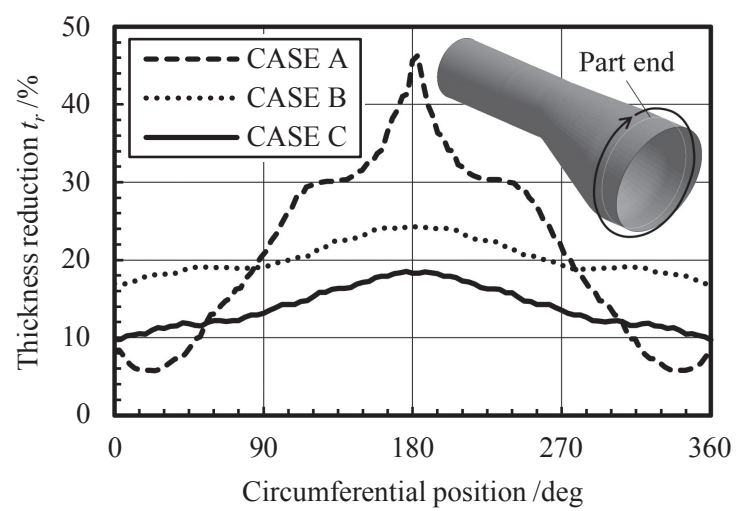

Fig. 17 Distribution of thickness reduction of part end in final step along the circumferential direction for each case.

and CASE B. In particular, the thickness reduction of part end at the $180^{\circ}$ circumferential position is suppressed by about $60 \%$ compared with CASE A.

$\mathrm{FE}$ analysis in this time was examined the dynamic explicit method using shell element, but it is reported that the result differs depending on the type of finite element and the type of solution method. ${ }^{11)}$ In the future, we will carry out forming tests to understand the actual deformation behavior, and verify differences from FE analysis.

\section{Conclusion}

In multiprocess tube flaring of expanded eccentric parts, we studied the effect of punch shape by FE analysis and the following findings were obtained.

(1) As a result of examining forming only with an eccentric punch (CASE A), the thickness deviation in the circumferential direction occurs and the thickness reduction increases because the tube is expanded greatly at the $180^{\circ}$ circumferential position.

(2) The thickness deviation and the thickness reduction in the circumferential direction are suppressed by using the forming method with a concentric punch (CASE B) instead of expanding the tube on one side with an eccentric punch. 
(3) Although the punch shoulder radius $R$ has little effect on formability, the deformation transitions near the tube edge from uniaxial tension to pure shear as the punch semiangle $\alpha$ increases.

(4) The thickness reduction is significantly suppressed compared with CASE A and CASE B by using the developed method (CASE C) of forming with a concentric punch having a punch semiangle $\left(\alpha=50^{\circ}\right)$ larger than the taper angle of $29^{\circ}$ from the initial step of forming. In particular, the thickness reduction of part end at the $180^{\circ}$ circumferential position is suppressed by about $60 \%$ compared with CASE A. As the result of this study, it was clarified that the guidelines of design in multiprocess tube flaring to improve formability.

\section{REFERENCES}

1) The Japan Society for Technology of Plasticity: Tube Forming -Forming Technology and Products Design- (Corona Publishing, Tokyo, 1992) pp. 114-127.

2) H. Nishimura and M. Miyagawa: J. JSTP 13 (1972) 493-501.

3) K. Manabe and H. Nishimura: J. JSTP 24 (1983) 47-52.

4) K. Manabe and H. Nishimura: J. JSTP 24 (1983) 276-282.

5) K. Manabe: Ph.D. thesis, Tokyo Metropolitan University, (1985).

6) K. Manabe and A. Tsuchiya: Proc. of Jpn. Soc. Mech. Eng., (2005) $627-628$.

7) K. Manabe and K. Nakata: Proc. of Jpn. Soc. Mech. Eng., (2007) 633634.

8) H. Suzuki: Tetsu-to-Hagané 46 (1960) 498-520.

9) M. Nakamura: Paipu-Kakouhou, (Nikkan-Kogyo-Shimbun-Sha, Tokyo, 1982) p. 69.

10) K. Kitazawa and M. Kobayashi: J. JSTP 28 (1987) 1267-1274.

11) T. Hama: J. JSTP 51 (2010) 1017-1022. 